\title{
An Awakening Alarm for Dental Professionals in Pandemic of Covid-19
}

\author{
Aditi Vinay Chandak ${ }^{1}$, Surekha Dubey Godbole², Tanvi Rajesh Balwani ${ }^{3}$, Tanuj Sunil Patil ${ }^{4}$ \\ 1,2,3 Department of Prosthodontics, Sharad Pawar Dental College, Wardha, Maharashtra, India. \\ ${ }^{4}$ Department of Oral Surgery, Sharad Pawar Dental College, Wardha, Maharashtra, India.
}

Ecosystem, which consists of the physical environment and all the living organisms, on which we all depend, is declining rapidly because of its destruction caused by humans. It's a two-way relationship between the humans and mother nature. If we destroy the natural environment around us, human life will be seriously affected, and the life of next generation will be endangered unless serious steps are taken. One such effect of human overexploitations has come in the form of coronavirus outbreak.

Coronavirus, a contagious disease of 2019 known as Covid-19, is the latest swiftly spreading global infection. The aetiology of Covid-19 is different from SARS-CoV which has the severe acute respiratory syndrome coronavirus 2 (SARS-CoV-2), but it has the same host receptor, human angiotensin converting enzyme 2 (ACE2). The novel coronavirus which is zoonotic (spreading from an animal to a human) and mainly found in the bats and pangolins is a single stranded ribonucleic acid virus of Coronaviridae family. ${ }^{1}$ The typical structure of $2019-\mathrm{nCoV}$ possessed 'spike protein' in the membrane envelope, also expressed various polyproteins, nucleoproteins and membrane protein. The $\mathrm{S}$ protein binds to the receptor cell of host to facilitate the entry of virus in the host. Currently four genera for coronavirus are found $\alpha-\mathrm{CoV}$, $\beta$ $\mathrm{CoV}, \gamma-\mathrm{CoV}, \delta$-CoV. SARS-CoV first originated in Wuhan, China and has spread across the globe. World Health Organization (WHO) and public health emergency of international concern declared it as 2019 - 2020 pandemic disease. ${ }^{2}$ According to WHO report, ( $7^{\text {th }}$ April 2020) update on this pandemic coronavirus disease, there have been more than 13,65,004 confirmed cases and 76,507 deaths across the world and these figures are rapidly increasing. Therefore, actions for proper recognition, management and its prevention must be prompted for relevant alleviation of its outspread. ${ }^{3}$

Health care professionals are mainly indulged in the national crises and are working diligently around-the-clock, small ratio of the health care workers have become affected and few died tragically. Dentists are most often the first ones to be affected because they work with patients in close proximity. On 15th March 2020, the New York Times published an article titled "The workers who face the greatest Coronavirus risk" described the dentists are highly exposed, than the paramedical staffs and general physicians, to the risk of novel coronavirus disease 19.4

\section{Symptoms}

Infectious patients of coronavirus disease usually show clinical symptoms of sore throat, fever $\left(>100.4^{\circ} \mathrm{F}=38^{\circ} \mathrm{C}\right)$, cough, dyspnoea, myalgia and loss of taste. Abnormal detection such as ground glass opacities with increased attenuation of the lung parenchyma are typically seen on chest x-ray and computed tomography. ${ }^{5}$

Most of the patients, present with mild flu-like and seasonal-allergy symptoms, which may remain undiagnosed. ${ }^{6}$ SARS-CoV-2 is highly transmissible and has an incubation period of $0-24$ days, therefore the symptoms may appear anytime. ${ }^{7}$ Patients with pre-existing immunosuppressive illness such as diabetes, cardiovascular diseases and males have a strong predilection of severe form of diseases with age ranging from 50 - 58 years. The acute respiratory distress syndrome and symptoms of typical pneumonia is manifested by high-risk patient population. ${ }^{5}$
Corresponding Author: Dr. Aditi Vinay Chandak, 202, Department of Prosthodontics, Sharad Pawar Dental College, Wardha, Maharashtra, India. E-mail: adichandak18@gmail.com

DOI: $10.14260 /$ jemds $/ 2021 / 235$

How to Cite This Article:

Chandak AV, Godbole SD, Balwani TR, et al. An awakening alarm for dental professionals in pandemic of Covid-19. J Evolution Med Dent Sci 2021;10(15):10981101, DOI: 10.14260/jemds/2021/235

Submission 26-08-2020,

Peer Review 27-12-2020

Acceptance 04-01-2021,

Published 12-04-2021.

Copyright (c) 2021 Aditi Vinay Chandak et al. This is an open access article distributed under Creative Commons Attribution License [Attribution 4.0 International (CC BY 4.0)] 


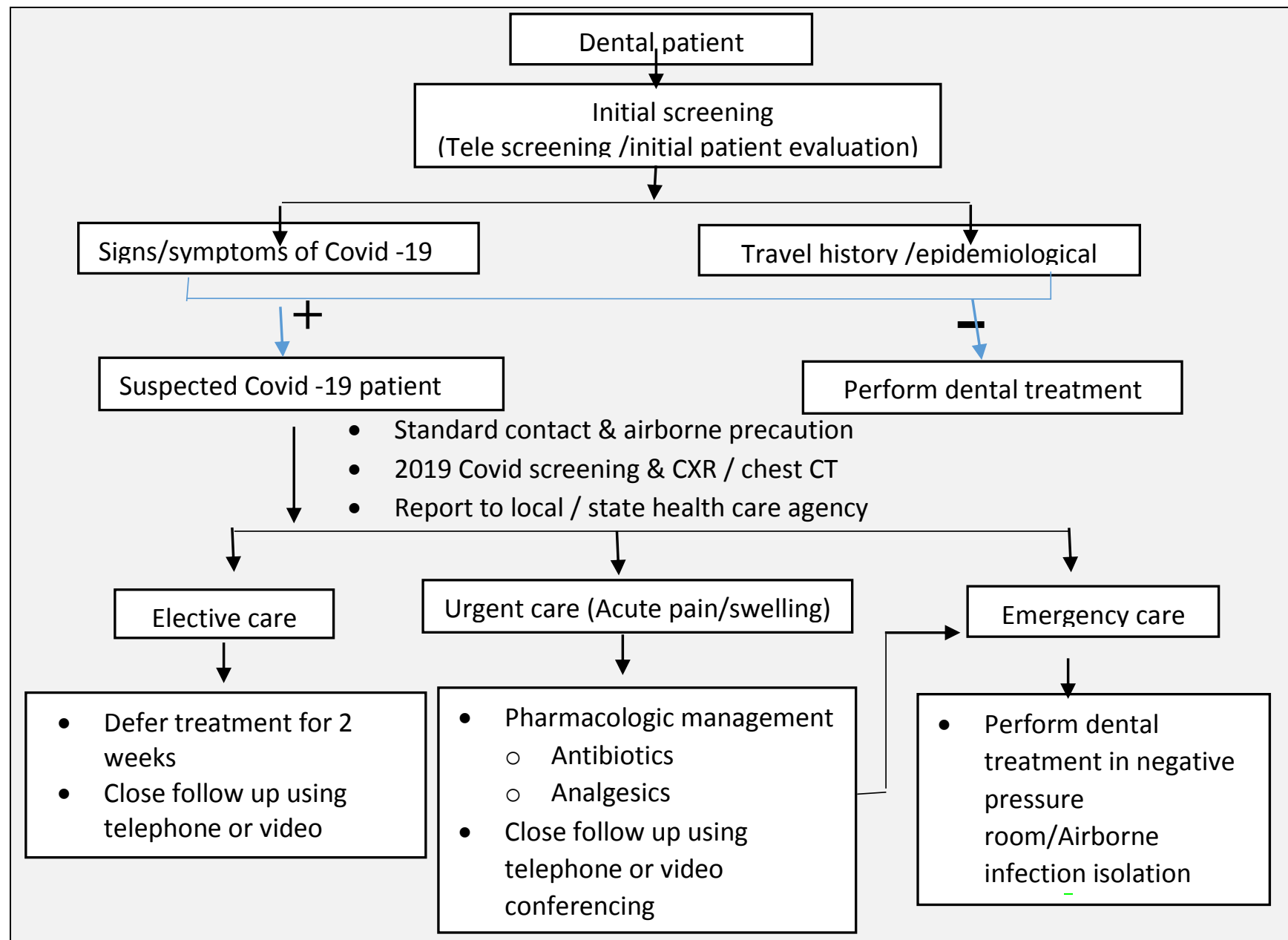

Figure 1. Specific Measures for the Management of Covid-19 Patients in Dental Clinic

\section{Modes of Transmission}

Coronavirus spreads via droplets of respiratory mucous or by close connection. SARS-CoV-2 spreads through air and potentially infect the people through cough and sneeze of an infected person to others who are in close contiguity (around 6 - 6.5 feet's). Therefore, social distancing has been recommended. These droplets if deposited on the objects placed in vicinity of infected patients, can make even healthy individual infected. This transmission occurs via touching the surface of contaminated surface. ${ }^{8}$ Thus, the frequent handwashing (after 20 mins) with soaps or sanitizer and disinfection of objects with approved chemicals is advised. In recent report, it is suggested that the virus may remain viable on hard surfaces up to 9 days; therefore, it is essential to wash and disinfects in intervals. Presence of CoV2 has also been reported in the excretions of infected person including their saliva and faeces. ${ }^{9,10}$ This coronavirus has high affinity to be in secretory saliva as they can bind to human angiotensin converting enzyme (ACE) positive cells which are mainly concentrated in human saliva. ${ }^{11}$ Therefore, there is potential risk of transmission via aerosols, fomites or faecal-oral route. The dental clinic under such scenario can also be considered as a source of nosocomial CoV infection. ${ }^{12}$ Studies have suggested that aerosol formed during dental procedures can transmit the Covid-19. It can be detected by real-time reverse transcription polymerase chain reaction (rRt-PCR) testing in stool specimen collected on $7^{\text {th }}$ day of illness. The droplet and aerosol transmission of Covid-19 is important in dental set up because it is difficult to keep away the large amount of aerosol and patients' blood mixed with droplets and saliva during a clinical procedure. The spread of pathogenic microorganisms can occur through inhalation of microorganisms present in aerosol, direct contact of saliva and blood or through other means as this is an airborne infection. ${ }^{13}$

\section{Patient Management and Preventive Measures of Nosocomial Infections}

The American Dental Association on 16 th March 2020 has recommended to delay the selective dental procedures for 3 weeks and just to provide treatment for dental emergencies.

Certain specific measures are given in the following flow chart for management of Covid-19 patients in this pandemic period.

Dental professionals must be able to recognise the Covid19 disease. Firstly, the body thermal screening of each and every patient must be checked. If the patient is febrile, he/she must be instructed for self-quarantine and report, for the other symptoms, to health department. The patients should develop a regular reporting system about the travel history or a history of contact with person of suspected infection or confirmed case. Dentists when imparting treatment to probable or positive Covid-19 patients, the following recommendations should be acquainted -

1. Hand washing techniques must be followed before examining the patient, before starting of the dental 
procedures and after completion of procedure. All dental professionals should take cautions to avoid touching their eyes, nose and mouth.

2. The standard norms and airborne safety measures including the proper use of personal protective equipments (PPE) along with adequate hand hygiene must be follow by the dentists. Three level protective measures are recommended.

3. A. Primary protection: Standard protection of wearing disposable head caps, surgical mask, protective goggles, disposable latex gloves and white coats (working clothes). B. Secondary protection: Advanced protection with primary protection and disposable of isolation clothing or surgical clothes outside.

C. Tertiary protection: It is to strengthened protection for patients in contiguity with suspected or confirmed case. Additional protection with all PPE and use of impermeable shoe cover, extra disposable protective clothing should be worn. ${ }^{13}$

The Centers for Disease Control and Prevention (CDC) has given the directions on how to wear and carry off the PPE. ${ }^{14}$

4. Mouth rinse before procedure: Research has found that SARS and MERS were significantly sensitive to povidone iodine mouth rinse. Hence, $0.2 \%$ povidone iodine or $1 \%$ hydrogen peroxide should be used for rinsing before every procedure which might decrease the load of coronavirus in saliva. ${ }^{15}$

5. To prevent the cross-contamination, disposable (single use) devices like diagnostic instruments, needle and syringes are recommended.

6. Intraoral imaging radiographs might lead to gag reflex and cough, to avoid this extra oral imaging like cone-beam computed tomography (CBCT), panoramic should be used. If intraoral imaging is mandatory then to avoid cross contamination and perforation, sensors should be double barriered. 16,17

7. For isolation, a rubber dam must be used to minimise the splatter generation and the four handed dentistry technique can be beneficial for controlling the infection. If rubber dam isolation is not possible then manual devices such as minimal invasive procedure by using chemo mechanical method for caries removal and hand scalers can be used for periodontal scaling, to keep down the generation of aerosol as much as possible.

8. High speed hand pieces, three-way syringes and ultrasonic devices should be reduced to minimise the generation of aerosols. Hand piece with high speed without retraction valve during procedure may aspirate and exile the debris or fluids and it may contaminate the water tubes and air within dental unit, therefore antiretraction hand piece must be used as an extra preventive measure for cross infection.

9. Negative pressure treatment room / air borne infection isolation rooms (AIIRs) should be used to treat suspected or confirmed Covid-19 cases. $^{14}$

10. Biomedical waste generated by the infectious patients of Covid-19 should be segregate properly and disposed of in yellow colour double layered package bag with gooseneck.

11. Clinical staff should ensure disinfection of non-living objects with the help of approved disinfectants. It is imperative that a dry and hygienic environment should be maintained.

12. Hand pieces, impression trays and burs should be autoclaved after completing of procedure of each patient.

The rapid spread of coronavirus disease globally is growing the prospect that dental health care professionals will have to provide treatment to these patients. Precautions are very important to minimise the spread of this infectious disease. It is necessary to treat confirmed cases of Covid-19 patients with additional measures and further precautions should be taken.

As incubation period may vary in every individual $(0-24$ days) every patient should be considered as likely infected and dental procedures have to be performed very carefully with infection control protocols.

Adequate training should be given to the health care staff and there should be all levels of screening and preventive measures for the dental professionals to restart the dental procedures while reducing the spread of this pandemic coronavirus disease.

\section{CONCLUSIONS}

With time, this new emerging SARS-CoV-2 could become more common infection causing less threat and less pathogenic in the worldwide population. Health care professionals have the responsibilities of protecting and preventing the people from getting infected by following the infection control protocols. It is important to educate and increase the awareness among the public via mass media to prevent fright at these tough times by promoting the health and wellbeing of patients. Even people should be made aware about the clinical decisions. It is the responsibility of every citizen of the world to join hands and unite to fight against the novel coronavirus infection.

Financial or other competing interests: None.

Disclosure forms provided by the authors are available with the full text of this article at jemds.com.

\section{REFERENCES}

[1] Dong E, Du H, Gardner L. An interactive web-based dashboard to track Covid-19 in real time. Lancet Infect Dis 2020;20(5):533-4.

[2] Spagnuolo G, Vito DD, Rengo S, et al. Covid-19 outbreak: an overview on dentistry. Int J Environ Res Public Health 2020;17(6):2094.

[3] Ather A, Patel B, Ruparel NB, et al. Coronavirus disease 19 (Covid-19): implications for clinical dental care. J Endod 2020;46(5):584-95.

[4] Gamio L. The workers who face the greatest coronavirus risk.

https://www.nytimes.com/interactive/2020/03/15/bu siness/economy/coronavirus-worker-risk.html? action $=$ click\&module $=$ Top + Stories \&pgtype $=$ Homepage

[5] Lan L, Xu D, Ye G, et al. Positive RT-PCR test results in patients recovered from Covid-19. JAMA 2020.

[6] Giacomelli A, Pezzati L, Conti F, et al. Self-reported olfactory and taste disorders in patients with severe acute 
respiratory coronavirus 2 patients: a cross-sectional study. Clin Infect Dis 2020;71(15):889-90.

[7] Guan WJ, Ni ZY, Hu Y, et al. Clinical characteristics of 2019 novel coronavirus infection in China. medRxiv 2020. https://www.medrxiv.org/content/10.1101/2020.02.06 $.20020974 \mathrm{v} 1$.

[8] Centers for Disease Control and Prevention. Transmission of coronavirus disease 2019 (Covid-19). https://www.cdc.gov/coronavirus/2019ncov/about/transmission.html.

[9] Rothe C, Schunk M, Sothmann P, et al. Transmission of 2019-nCoV infection from an asymptomatic contact in Germany. N Engl J Med 2020;382(10):970-1.

[10] Kwok YLA, Gralton J, McLaws ML. Face touching: a frequent habit that has implications for hand hygiene. Am J Infect Control 2015;43(2):112-4.

[11] To KK, Tsang OT, Yip CC, et al. Consistent detection of 2019 novel coronavirus in Saliva. Clin Infect Dis 2020;71(15):841-3.

[12] Hoffmann M, Kleine-Weber H, Schroeder S, et al. SARSCoV-2 cell entry depends on ACE2 and TMPRSS2 and is blocked by a clinically proven protease inhibitor. Cell 2020;181(2):271-80.

[13] Peng X, Xu X, Li Y, et al. Transmission routes of 2019-nCoV and controls in dental practice. Int J Oral Sci 2020;12:9.

[14] Wang Y, Wang Y, Chen Y, et al. Unique epidemiological and clinical features of the emerging 2019 novel coronavirus pneumonia (Covid-19) implicate special control measures. J Med Virol 2020;92(6):568-76.

[15] Centers for Disease Control and Prevention. Infection control: severe acute respiratory syndrome coronavirus 2 (SARS-CoV-2). https://www.cdc.gov/coronavirus/2019ncov/ infection-control/control-recommendations.html.

[16] Kariwa H, Fujii N, Takashima I. Inactivation of SARS coronavirus by means of povidone-iodine, physical conditions and chemical reagents. Jpn J Vet Res 2004;52(3):105-12.

[17] Gondivkar SM, Bhowate RR, Gaidbail AR, et al. Quality of life and oral potentially malignant disorders: critical appraisal and prospects. World J Clin Oncol 2018;9(4):569. 